\title{
USING FUZZY SET APPROACH IN MULTI-ATTRIBUTE AUTOMATED AUCTIONS
}

\author{
Madhu Goyal \\ Faculty of Engineering and Information Technology, UTS, Broadway, Australia \\ madhu@it.uts.edu.au \\ Saroj Kaushik \\ Indian Institute of Technology, Delhi, India \\ saroj@cse.iitd.ernet.in
}

Keywords: Automated Auctions, Bidding Strategy, Fuzzy Sets, Software Agents.

Abstract: $\quad$ This paper designs a novel fuzzy attributes and competition based bidding strategy (FAC-Bid), in which the final best bid is calculated on the basis of the assessment of multiple attributes of the goods and the competition for the goods in the market. The assessment of attributes adapts the fuzzy sets technique to handle uncertainty of the bidding process. The bidding strategy also uses and determines competition in the market (based on the two factors i.e. no. of the bidders participating and the total time elapsed for an auction) using Mamdani's Direct Method. Then the final price of the best bid will be determined based on the assessed attributes and the competition in the market using fuzzy reasoning technique.

\section{INTRODUCTION}

Online auctions (e.g. eBay and Amazon) are popular market institutions for conducting transactions between the buyers and the sellers. The software agent technology is well known paradigm in on-line auctions for buying and selling the goods. Software agents provide automated assistance for trading through the knowledge of the market and the requirements of the market (Rahman and Robert 2001).The agents can use different auction mechanisms (e.g. English, Dutch, Vickery etc.) for procurement of goods or reaching agreement between agents. The agent makes decisions on behalf of consumer and endeavours to guarantee the delivery of item according to the buyer's preferences. In these auctions buyers are faced with difficult task of deciding amount to bid in order to get the desired item matching their preferences. The bidding strategies for the software agents can be static or it may be dynamic. The static agents may not be appropriate for the negotiating market situations like extent of competition may vary as traders leave or enter into the market, deadlines and new opportunities may increase the pressure. The dynamic or we can say flexible negotiation capabilities for software agents in the online auctions have become a central concern (Murugesan 2000). Agents need to be able to prepare bids and evaluate offers on behalf of the users they represent with the aim of obtaining the maximum benefit ( $\mathrm{Ma}$ and Leung 2007) for their users according to the changing market situation. Much research has already been done by the researchers to formulate different bidding strategies according to the changing market situations.

Strategies based on flexible negotiation agents perform better as compared to the strategies based on fixed negotiation agents (Kwang and Wang 2004). Faratin et al (Faratin, Sierra and Jennings 1998) developed strategies based on time, attitude, resources, but many more factors such as competition, trading alternatives are not considered: In this paper we focus on the design of a novel bidding strategy based on the above mentioned factors to be used by the software agent in a online auction. A fuzzy attributes and competition based bidding strategy(FAC-Bid) is designed, in which the final best bid is calculated on the basis of the assessment of the attributes of the goods as well as the competition for these goods in the market. 


\section{A FUZZY ATTRIBUTE AND COMPETITION BASED BIDDING STRATEGY (FAC-BID)}

In fuzzy attribute and competition based bidding strategy (FAC-Bid) (Fig. 1), the factors which are focused are assessing attributes of the goods and competition for the goods in the market. For estimation of the price for a bid for winning an auction, the agent must have a balanced behaviour between these factors i.e. the assessment of the good's attributes and finding the competition for the goods in the market. The bidding price of the quality goods is more as compared to the less quality goods. Also the increasing competition for the goods in the market increases the bidding price for that good. The competition in turn depends on the number of bidders and the time elapsed for the auction. As the number of bidders increases, the competition among them also increases, resulting in a higher price. In the beginning of the auction the competition is less and it increases as time elapses and it is at the peak when time approaches approximately in the middle of the auction period. At the end of the auction period the competition among the bidders decreases.

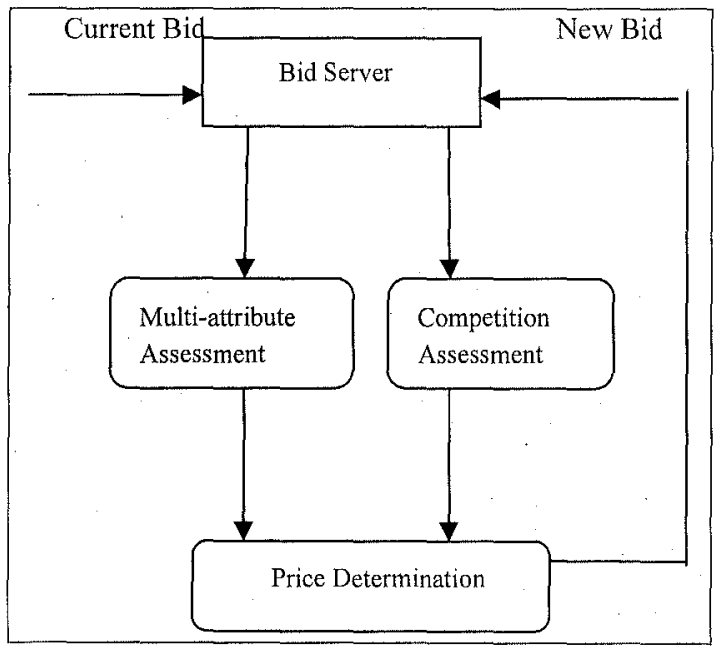

Figure1: A Fuzzy Bidding Strategy (FAC-Bid) Mode.

The steps of the design of fuzzy attribute and competition based bidding strategy (FAC-Bid) are as follows:

- First, each attribute is evaluated
- Then the assessment of all these attributes will be aggregated to form an overall assessment of the goods.

- next the level of competition as the function of no. of bidders and time elapsed for the auction will be found

- Finally the best bid is calculated on the basis of the overall assessment of the good's attributes and the competition for the goods in the market.

In this paper we have used fuzzy set methods to deal with the uncertainty, which exists during the determination of overall assessment of the goods for their attributes, the level of competition in the market and to find the final bid price. First of all, this paper uses a satisfactory degree measure as the common universe of assessment, i.e., an assessment is treated as a fuzzy set on the satisfactory degree. Secondly, competition is expressed as a fuzzy set on the fuzzy sets of the no. of bidders and the time elapsed of the auction. Thirdly, bid displacement factor for finding the final bid is expressed as a fuzzy set on the fuzzy set of assessment of the attributes and the competition for the goods in the market.

\subsection{Attribute Evaluation}

The attribute evaluation is done in two parts (Goyal and $\mathrm{Ma}$ 2009). The first one is individual attribute assessment and the second one is assessment aggregation. To implement attribute evaluation, three issues are concerned i.e. attribute weights (relative importance) adjustment, assessment expression and assessment aggregation.

Weight Adjustment. Weight adjustment implements dynamically change relative importance of multiple criteria. In a real situation an agent's personal preference on the attributes seldom has quickly fluctuation, i.e., the weights for criteria is relatively stable in a long run. The adjustment of weights resulted from the price should be limited to a rational range. Moreover, the adjustment shouldn't change the relative significance among criteria other than the price because raising price alters the relative significance of it to other criteria. In the following, the agent's preference is treated as an initial weight vector which is the basis of the adjustment. To construe an initial weight vector, the Analytic Hierarchy Process (AHP) method is applied because it is proved validate in practice although it may induce inner inconsistency. Suppose obtained initial weight vector is $\mathrm{W}^{(0)}$.

Suppose the current bid $p_{c}$ belongs to $\left[p_{1}, p_{u}\right]$ where $p_{i}$ and $p_{u}$ are the lower and upper boundaries 
of possible bids respectively which are determined by the auction. Let $\mathrm{C}=\left\{\mathrm{c}_{0}, \mathrm{c}_{1}, \ldots, \mathrm{c}_{\mathrm{K}}\right\}$ be the set of $\mathrm{K}+1$ attributes and $\mathrm{W}=\left\{\mathrm{w}_{0}, \mathrm{w}_{1}, \ldots, \mathrm{w}_{\mathrm{K}}\right\}$ is the set of weights for attributes in C. Because except the price agent's assessments on other criteria do not change, the adjustment of weight for price should be determined first. Suppose $[-\delta, \delta]$ is the adjustable range of the weight for price and the current net increasing of weight for price is $\Delta w_{0}$, then the current weight vector is determined by

$$
\begin{aligned}
& \mathrm{w}^{\prime}{ }_{0}=\mathrm{w}_{0}+\Delta \mathrm{w}_{0} \\
& w^{\prime}{ }_{k}=w_{k} \frac{1-w_{0}^{\prime}}{1-w_{0}}
\end{aligned}
$$

where $w_{k}(k=0,1, \ldots, K)$ is the component of $W^{(0)}$.. Obviously,

$$
\sum w_{k}=1 \quad \text { for } k=0 \text { to } 1
$$

and the relative significance of the criteria except for the price will not change after this adjustment.

Assessment Expression. Since uncertain expressions are often used in a real situation, this paper uses linguistic terms to express assessments. These linguistic terms are illustrated by fuzzy set. Moreover, the universe of these fuzzy set are unified to real interval $[0,1]$ which means the satisfactory degree of the agent to a particular attribute.

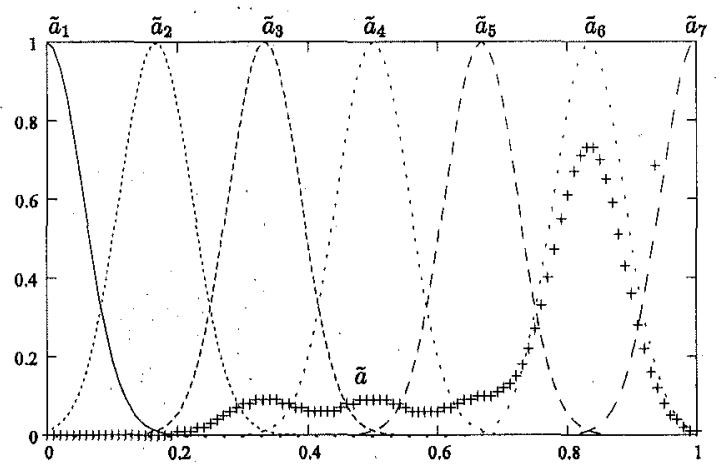

Figure 2: Obtain overall assessment.

Therefore, all fuzzy sets have same universe which is convenient for aggregating assessments. Let $g_{k}(k$ $=0,1, \ldots, \mathrm{K}$ ) is the satisfactory degree measure for attribute $c_{k}$. Then an agent's opinion on the goods in terms of attribute ck is denoted by $g_{k}(u)$ where $u(E$ $U_{k}$ ) is the real attribute value of attribute $c_{k}$ and $U_{k}$ is the real universe for attribute ck. For instance, departing time is an attribute for a flight ticket. The possible departing time in a day is from 0:00 to 23:59. For any time slot u, a client may present a satisfactory degree such as departing at 7:30 is with satisfactory degree 0.9 and departing at $3: 00$ is with 0.3 . In the following, $A=\left\{a_{1}, \ldots, a_{n}\right\}$ be the set of used assessment terms which are fuzzy sets on satisfactory degree $[0,1]$. Then a numeric satisfactory degree is transformed to a linguistic term. In the above example, suppose the assessment set is as shown in figure 2 . Notice that a7 is with the biggest membership degree for 0.9 , the assessment for departing at $7: 30$ is $a_{6}$ by the maximum membership degree principle. Similarly, the assessment for 0.3 is $a_{2}$.

Assessments Aggregation. An aggregated assessment is the agent's overall opinion/preference on the goods in terms of multiple attributes. Take booking a flight ticket for example, an assessment is made on a ticket usually based on the airlines, flight departure and arrival time, flight type, aircraft types, seat positions, as well as price. The change of an attribute's value may leads to the alternation of an assessment. Instinct natures of different attributes increase the difficulty and uncertainty for obtaining an overall assessment. Notice that an agent's preference on an individual attribute can be expressed through the agent's satisfactory degree on that attribute. This paper uses an satisfactory degree measure as the common universe of assessment. Based on assessment on each individual attribute, an overall assessment can be obtained as follows. Suppose the individual assessments of all attributes are $v_{m}, v_{1}, \ldots, v_{k}$ and the weights of them are $w_{0}$, $w_{1}, \ldots, w_{k}$ respectively. Then an overall assessment is obtained by

$$
a=\operatorname{Agg}\left\{\left(\mathrm{v}_{0}, \mathrm{w}_{0}\right),\left(\mathrm{v}_{1}, \mathrm{w}_{1}\right), \ldots,\left(\mathrm{v}_{\mathrm{K}}, \mathrm{w}_{\mathrm{K}}\right)\right\}
$$

where Agg is a selected aggregation method, $v_{k} \in A$ $(k=0,1, \ldots, K)$ is the linguistic assessment on attribute $c_{k}$. To get an overall assessment in terms of a set of criteria, an aggregation method Agg is applied. Here we use the weighted-sum-based method to obtain an overall assessment as follows. First, we construct a fuzzy set ã on $[0,1]$ through

$$
\tilde{\mathrm{a}}(u)=\sum w k \cdot v k(u), \quad u \in[0,1] \text { for } k=0 \text { to } 1
$$

where $v k(u)$ is the membership degree of $u$ in $v k$. Next, we calculate the distance between $\tilde{\mathrm{a}}$ and $a_{i} \in$ A, by

$$
d\left(\tilde{\mathrm{a}}, a_{i}\right)=\int\left|\tilde{\mathrm{a}}-a_{i}\right| \mathrm{d} \lambda .
$$

Finally, we select the nearest term(s) $a$ to ã as the overall assessment. For example, A has seven terms, namely, $a_{1}, a_{2}, \ldots . a_{7}$ as shown in figure 2 . Suppose ã is the obtained fuzzy set. By comparing the distances between ã and each element in $A$, we know $a_{6}$ is the 
nearest item to ã. Hence, $a_{6}$ will be taken as the overall assessment.

\subsection{Competition Assessment}

The level of competition in an auction may be captured by the number of bidders and the time elapsed. Competition among bidders plays an integral role in price formation (Reddy and Dass 2006). As the number of bidders increases, the competition among them also increases, (Fig. 3) resulting in a higher price. Bapna, Jank and Shmueli found the number of bidders to be positively associated with the current price of the item. Furthermore, it is observed that, typically, the middle of the auction experiences a smaller amount of bidder participation as compared to the early and later stages of the auction. Bidders generally utilize this time to scrutinize the auctioned item or just simply wait to see how other bidders behave. Therefore, it would be interesting to see how this competition characteristic affects the on-line auction's price formation. We anticipate that the number of bidders has a significant positive relationship with price levels. In the beginning of the auction the competition is less and it increases as time elapses and it is at the peak when time approaches approximately in the middle of the auction period. At the end of the auction period the competition among the bidders decreases (Fig. 4).

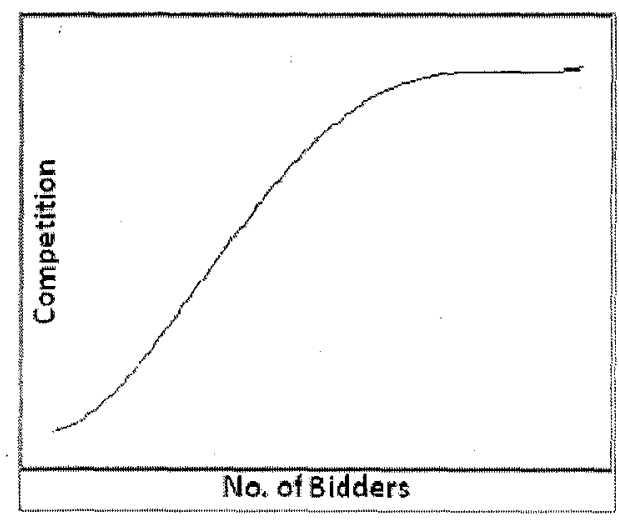

Figure 3: Competition versus Number of Bidders.

Here we will describe the competition factor in terms of no. of bidders (b) and the total time elapsed (t) for the auction of items. We will consider the competition as a set fuzzy set of values $c_{1}, c_{2}, \ldots \ldots c_{n}$, no. of bidders $B$ as a fuzzy set of values $y_{1}, y_{2} \ldots \ldots y_{n}$. And the time elapsed as another fuzzy set $\mathrm{T}$ of values $\mathrm{x}_{1}, \mathrm{x}_{2}, \ldots . \mathrm{x}_{\mathrm{n}}$. According to Mamdani's Direct
Method (Tanaka 1991) we can find adaptability n no. of rules $w_{1}, w_{2}, \ldots \ldots . . w_{n}$ as

$$
\mathrm{w}_{\mathrm{i}}=\mu \mathrm{x}_{\mathrm{i}}(\mathrm{T}) \vee \mu \mathrm{y}_{\mathrm{i}}(\mathrm{B}) \text { for } \mathrm{i}=1 \text { to } \mathrm{n}
$$

Then the conclusion of each rule can be found as

$$
\mu c^{\prime}{ }_{i}(C)=w_{i} \vee \mu c_{i} \text { for } i=1 \text { to } n
$$

These conclusions can be aggregated to find the final conclusion

$$
\mu \mathrm{c}(\mathrm{C})=\mu \mathrm{c}^{\prime}{ }_{1}(\mathrm{C}) \wedge \mu \mathrm{c}^{\prime}{ }_{2}(\mathrm{C}) \wedge \ldots \ldots \ldots \ldots{ }^{\wedge} \mu \mathrm{c}^{\prime}{ }_{\mathrm{n}}(\mathrm{C})
$$

To find the definite value for the conclusion, here centre of gravity of the fuzzy set has been applied as follows

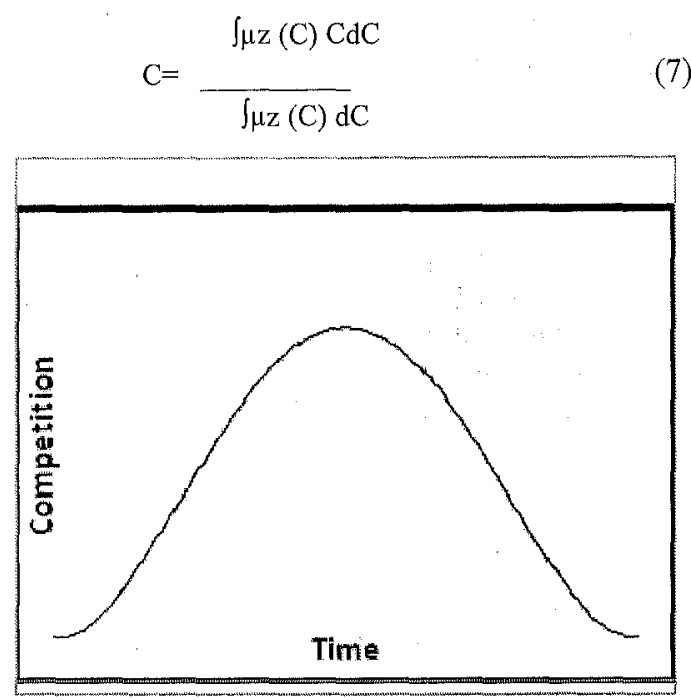

Figure 4: Competition versus Time Elapsed.

\subsection{Agent Price Determination}

Price of the goods depends on the assessed attributes of the goods and the competition in the market for that good. If the assessment of the attributes of the goods is good and also competition for that product in the market is high then the price of the item is high. If the assessment of the attributes of the goods bad and competition is also low then the price for that item is obviously be low. If the attribute's assessment is good and the competition is low then the price is going to be medium and so on.

We can calculate the price of the good based on the assessed attributes and the competition determined which is based on the no. of bidders and time elapsed for the auction by applying Mamdani's Method for fuzzy relations and compositional rule of inference (Tanaka 1991). Here we will describe the price of goods in terms of assessment of the attributes of the goods and competition in the market 
for that good. We will consider bid displacement factor $\Delta \mathrm{P}$ as a fuzzy set of values $\mathrm{p}_{1}, \mathrm{p}_{2}, \ldots \ldots \ldots \mathrm{p}_{\mathrm{n}}$, assessment of the attributes $A$ as a fuzzy set of values $a_{1}, a_{2}, \ldots \ldots, a_{n}$ and competition $C$ as a fuzzy set of values $c_{1}, c_{2}, \ldots \ldots \ldots c_{n}$. According to Mamdani's Method for fuzzy relations and compositional rule of inference the rule $a_{i}$ and $c j \rightarrow p k$ can described by

$$
\mu R(A, C, \Delta P)=\mu a_{i}(A)^{\wedge} \mu c_{j}(C)^{\wedge} \mu p_{k}(\Delta P)
$$

For $\mathrm{n}$ no. of rules, the compiled fuzzy relation $\mathrm{R}$ is given as

$$
\mathrm{R}=\mathrm{R}_{1} \mathrm{UR}_{2} \mathrm{U} \ldots \ldots \ldots \ldots \ldots \mathrm{UR}_{\mathrm{n}}
$$

For the input of fuzzy set $A^{\prime}$ on $A$ and fuzzy set $C^{\prime}$ on $\mathrm{C}$, the output fuzzy set $\Delta \mathrm{P}^{\prime}$ on $\Delta \mathrm{P}$ can be obtained as follows

$$
\Delta \mathrm{P}^{\prime}=\left(\mathrm{A}^{\prime} \text { and } \mathrm{C}^{\prime}\right) \mathrm{R}=\mathrm{A}^{\prime} \mathrm{O}\left(\mathrm{C}^{\prime} \mathrm{oR}\right)=\mathrm{C}^{\prime} \mathrm{O}\left(\mathrm{A}^{\prime} \mathrm{oR}\right)
$$

And then the final price for the bid will be Final bid $=$ Current bid $+\Delta \mathrm{P}$ '

\section{CONCLUSIONS}

In this paper we have designed a fuzzy attribute and competition based bidding strategy (FAC-Bid), which uses a soft computing method i.e. fuzzy logic technique to compute the final bid price based on the assessment of the attributes and the competition in the market. Another unique idea presented in this paper is that to deal quantitatively the imprecision or uncertainty of multiple attributes of items to acquire in auctions, fuzzy set technique is used. The bidding strategy also allows for flexible heuristics both for the overall gain and for individual attribute evaluations. Specifically, the bidding strategy is adaptive to the environment as the agent can change the bid amount based its assessment of the various attributes of item, and the competition in the auction .The competition is calculated based on the number of bidders and the time elapsed for the auction. It was noticed that the strategies in which agent's behaviour depends on attributes and competition, are easily adaptable to the dynamic situations of the market. In future we will investigate about the development of the bidding strategies for multiple auctions. We will also compare our bidding techniques with the other strategies to find out the relative strengths and the weaknesses.

\section{REFERENCES}

Rahman, S. M, Robert J,, 2001: Internet Commerce and Software Agents: Cases, Technologies Opportunities, Idea Group Publishing.

Murugesan, S., 2000.Negotiation by Software agents in Electronic Marketplace, in:TENCON'00, Proceedings of the 2000 IEEE Region 10 Conference on Intelligent Systems and Technologies for the new Millennium, Kuala Lumpur, Malaysia, pp.286--290.

Ma, H. Y., Leung, H. F., 2007: An Adaptive Attitude Bidding Strategy for Agents in Continuous Double Auctions. Electronic Commerce Research Applications, 6 (4). Elsevier, 383-398.

Kwang, S. M., Wang, S. Y., 2004 In IEEE Transactions on Systems, Man and Cybernetics- Part B: Cybernetics, Vol.34, No.3.

Faratin, P., Sierra, C. and Jennings, N. R., 1998. Negotiations decision functions for autonomous agents, In International Journal of Robot Autonomous System, Vol. 24, no. 3, pp 159-182,.

Goyal, M. L., Jun, M., 2009. Using Agents' Attitudes and Assessments in Automated Fuzzy Bidding Strategy. Proceeding of First International Conference on Agents and Artificial Intelligence, Porto, Portugal.

Reddy, S. K., Dass, M., 2006.Modeling On-Line Art Auction Dynamics Using Functional Data Analysis Statistical Science Vol. 21, No, 2, 179--193 Institute of Mathematical Statistics.

Bapna, R., Jank, W. and Shmueli, G., 2004. Price formation and its dynamics in online auctions. Working paper RHS-06-003, Smith School of Business, Univ. Maryland (2004).

Tanaka, K, 1991. An Introduction to Fuzzy Logic for Practical Applications, Axel Springer Verlag. 


\section{Paper Reviews}

Paper Title: USING FUZZY SET APPROACH IN MULTI-ATTRIBUTE AUTOMATED AUCTIONS

Paper \#: 158

Paper Selection State: Short Paper

My Status: Author

\section{Number of Reviews: 2}

\section{Review \#: 1}

\section{Criterium}

Abstract and Introduction are adequate?

Conclusions/ Future Work are convincing?

Figures are Adequate?

in number and quality

Improve critical discussion?

validation

Improve English?

Needs comparative evaluation?

Needs more experimental results?

Originality

Newness of the ideas expressed

Overall rating

Paper formatting needs adjustment?

Presentation

References are up-to-date and appropriate?

Relevance

Paper fits one or more of the topic areas? 
Scale: $\mathbf{1}$ :Lowest Value; 6 :Highest Value

\section{Observations for Author}

The topic is interesting and the approach is sound. However there are two major weaknesses that need to be improved: - Clear indication of what is your original contribution - Clear indication of what is the aimed purpose - only simulation or practical use (which)? It would also be necessary to have some comparison with results from related works.

\section{Review \#: 2}

\section{Criterium}

Abstract and Introduction are adequate?

Conclusions/ Future Work are convincing?

Figures are Adequate?

Improve critical discussion?

Improve English?

Description

Value

Yes

No

in number and quality

Yes

validation

Yes

No

Needs comparative evaluation?

Yes

Needs more experimental results?

Yes

Originality

Newness of the ideas expressed

5

Overall rating

Weighted value of above items

4

Paper formatting needs adj ustment?

No

Presentation

Structure/ Length/ English

5

References are up-to-date and appropriate?

Yes

Relevance

Paper fits one or more of the topic areas? 
Scale: $\mathbf{1}$ : Lowest Value; $\mathbf{6}$ :Highest Value

\section{Observations for Author}

This paper should pay more attention to comparative evaluation. 


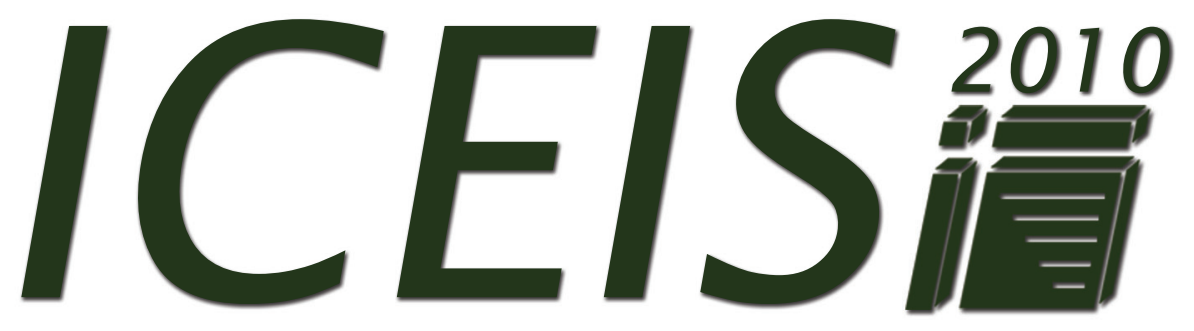

$12^{\text {th }}$ International Conference on Enterprise Information Systems

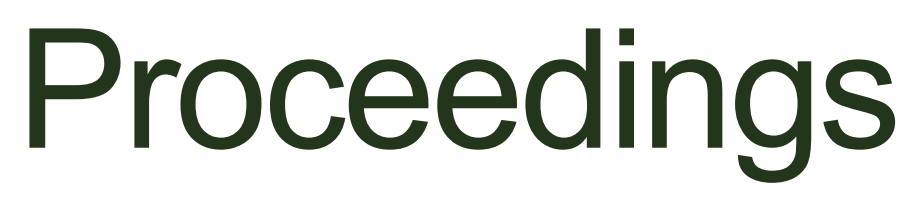

Volume 4

Funchal, Madeira - Portugal · 8 - 12 June, 2010

Sponsored by:

In Cooperation with:

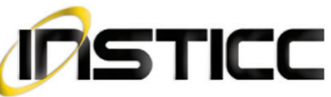

$\mathbb{A A}^{-\infty} \overline{W_{C}}$ SIGMIS \& SIGCHI 


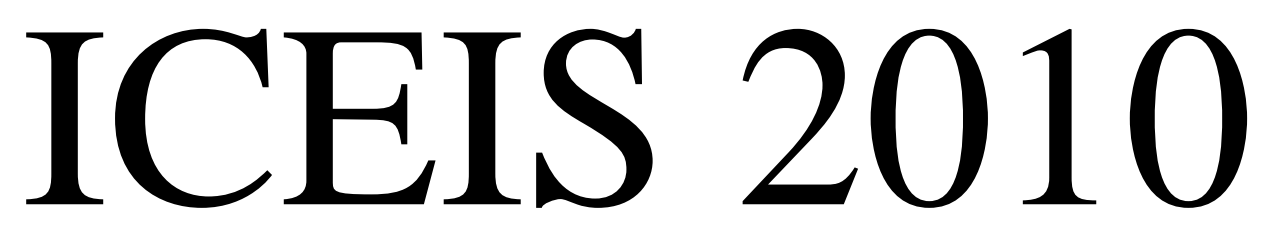

\author{
Proceedings of the \\ 12th International Conference on \\ Enterprise Information Systems
}

Volume 4

Software Agents and Internet Computing

Funchal, Madeira, Portugal

June $8-12,2010$

Sponsored by

INSTICC - Institute for Systems and Technologies of Information, Control and Communication

In Cooperation with

AAAI - Association for the Advancement of Artificial Intelligence

WfMC - Workflow Management Coalition

ACM SIGMIS - Association for Computing Machinery / Special Interest

Group on Management Information Systems

ACM SIGCHI - Association for Computing Machinery / Special Interest Group on Computer Human Interaction

ACM SIGART - Association for Computing Machinery / Special Interest

Group on Artificial Intelligence

IEICE SWIM - Institute of Electronics, Information and Communication

Engineers / Special Group on Software Interprise Modelling 
Copyright (C) 2010 SciTePress - Science and Technology Publications All rights reserved

Edited by Joaquim Filipe and José Cordeiro

Printed in Portugal

ISBN: 978-989-8425-07-2

Depósito Legal: 311155/10

http://www.iceis.org

iceis.secretariat@insticc.org 


\section{FOREWORD}

This volume contains the proceedings of the twelfth International Conference on Enterprise Information Systems (ICEIS 2010), sponsored by the Institute for Systems and Technologies of Information, Control and Communication (INSTICC), in cooperation with the Association for Advancement of Artificial Intelligence (AAAI), the Workflow Management Coalition (WfMC), the Association for Computation Machinery (ACM) Special Interest Group on Management Information Systems (SIGMIS), the ACM Special Interest Group on Computer Human Interaction (SIGCHI), the ACM Special Interest Group on Artificial Intelligence (SIGART) and the Institute of Electronics Information and Communication Engineers (IEICE) Special Interest Group on Software Interprise Modelling (SWIM).

This year ICEIS was held in Funchal-Madeira, Portugal. This conference has grown to become a major point of contact between research scientists, engineers and practitioners in the area of business applications of information systems, with five simultaneous tracks, covering different aspects related to enterprise computing, including: "Databases and Information Systems Integration", "Artificial Intelligence and Decision Support Systems", "Information Systems Analysis and Specification", "Software Agents and Internet Computing" and "Human-Computer Interaction". Papers published in each track describe state-of-art research work that is often oriented towards real world applications and highlight the benefits of Information Systems and Technology for industry and services, thus making a bridge between the Academia and the Enterprise worlds.

Following the trend of previous editions, ICEIS 2010 also had a number of satellite workshops, related to the field of the conference, including the following eight international workshops: 10th Int'l Workshop on Pattern Recognition in Information Systems; 8th Int'l Workshop on Modelling, Simulation, Verification and Validation of Enterprise Information Systems; 7th Int'l Workshop on Natural Language Processing and Cognitive Science; 5th Int'l Workshop on Technologies for Context-Aware Business Process Management; 4th Int'l Workshop on RFID Technology - Concepts, Applications, Challenges; 2nd Int'l Workshop on Future Trend of Model-Driven Development; 2nd Int'l Workshop on Advanced Enterprise Architecture and Repositories and the 1st Int'l Workshop on Recent Trends in SOA Based Information Systems.

ICEIS 2010 received 448 paper submissions from 58 countries on all continents. 62 papers were published and presented as full papers, i.e. completed work (10 pages/30' oral presentation) and 127 papers, reflecting work-in-progress, were accepted and orally presented as short papers (6 pages/20' oral presentation). Furthermore, 73 contributions were accepted and presented as posters.

These numbers, leading to a "full-paper" acceptance ratio around 13\%, and a total oral acceptance ratio of $42 \%$, show the intention of preserving a high quality forum for the next editions of this conference. Additionally, as usual in the ICEIS conference series, a number of invited talks, presented by internationally recognized specialists in different areas, have 
positively contributed to reinforce the overall quality of the Conference and to provide a deeper understanding of the Enterprise Information Systems field.

The program for this conference required the dedicated effort of many people. Firstly, we must thank the authors, whose research and development efforts are recorded here. Secondly, we thank the members of the program committee and the additional reviewers for a valuable help with their expert reviewing of all submitted papers. Thirdly, we thank the invited speakers for their invaluable contribution and for taking the time to synthesise and prepare their talks. Fourthly, we thank the workshop chairs whose collaboration with ICEIS was much appreciated. Finally, special thanks to all the members of the INSTICC organizing committee, especially Vitor Pedrosa, whose diligence and dedication was fundamental for the success of this conference.

Six best paper awards are given at the closing session to outstanding papers presented at the conference: an award for the top regular paper in each conference area plus an award for the best student paper, overall. The selection is based on the classifications and comments provided by the Program Committee and also on the oral presentation quality, assessed by session chairs.

A final selection of papers, from those presented at ICEIS 2010 in Funchal, will be done based on peer-assessment, i.e. on the classifications and comments provided by the Program Committee and on the assessment provided by session chairs. Extended and revised versions of these papers will be published in a book by Springer-Verlag.

We wish you all an exciting conference and an unforgettable stay in Funchal-Madeira. We hope to meet you again next year for the 13th ICEIS, to be held in Beijing, China, details of which will be readily available at http://www.iceis.org.

\section{Joaquim Filipe}

Polytechnic Institute of Setúbal / INSTICC, Portugal

\section{José Cordeiro}

Polytechnic Institute of Setúbal / INSTICC, Portugal 


\section{CONTENTS}

\section{INVITED SPEAKERS}

\section{KEYNOTE SPEAKERS}

PATTERN RECOGNITION AS A HUMAN CENTERED NON-EUCLIDEAN PROBLEM Robert P.W. Duin

IS-5

WIRELESS SENSOR NETWORKS (WSN) AND INTERNET OF THINGS (IOT)

Runtong Zhang

IS-7

CONTEMPORARY TRENDS IN ENTERPRISE INFORMATION SYSTEMS

David Olson

IS-9

GRAPH-BASED KNOWLEDGE REPRESENTATION AND REASONING

Michel Chein

IS-17

USABILITY AND CONTEXT-AWARE SYSTEMS

Anind K. Dey

IS-23

\section{SOFTWARE AGENTS AND INTERNET COMPUTING}

\section{Full Papers}

ASPECT-MONITOR - An Aspect-based Approach to WS-contract Monitoring Mario Freitas da Silva, Itana Maria de Souza Gimenes, Marcelo Fantinato, Maria Beatriz Felgar de Toledo and Alessandro Fabricio Garcia

LOCATING AND EXTRACTING PRODUCT SPECIFICATIONS FROM PRODUCER WEBSITES

Maximilian Walther, Ludwig Hähne, Daniel Schuster and Alexander Schill

QUERYABLE SEPA MESSAGE COMPRESSION BY XML SCHEMA SUBTRACTION

Stefan Böttcher, Rita Hartel and Christian Messinger

REPUTATION-BASED SELECTION OF WEB INFORMATION SOURCES

Donato Barbagallo, Cinzia Cappiello, Chiara Francalanci and Maristella Matera

TOWARDS AUTOMATED SIMULATION OF MULTI AGENT BASED SYSTEMS

Ante Vilenica and Winfried Lamersdorf

AN APPROACH FOR WEB SERVICE DISCOVERY BASED ON COLLABORATIVE STRUCTURED TAGGING

Uddam Chukmol, Aïcha-Nabila Benharkat and Youssef Amghar

\section{ShORT PAPers}

THE IMPACT OF COMPETENCES ASSESSMENT SYSTEMS TO FIRM PERFORMANCE Study on Project Management e-Assessment Maria-Iuliana Dascalu, Camelia Delcea, Dragos Palaghita and Bogdan Vintila

THE BEAUTY OF SIMPLICITY - Ubiquitous Microblogging in the Enterpise Peter Gluchowski and Martin Böhringer 
ADAPTING MULTIPLE-CHOICE ITEM-WRITING GUIDELINES TO AN INDUSTRIAL CONTEXT

Robert Michael Foster

IMPROVING MOODLE WITH WIRIS AND M-QIT

Ángel Mora, Enrique Mérida and Domingo López

USING FUZZY SET APPROACH IN MULTI-ATTRIBUTE AUTOMATED AUCTIONS

Madhu Goyal and Saroj Kaushik

81

ABSTRACTION FROM COLLABORATION BETWEEN AGENTS USING ASYNCHRONOUS MESSAGE-PASSING

Bent Bruun Kristensen

SERVICE ACQUISITION AND VALIDATION IN A DISTRIBUTED SERVICE DISCOVERY SYSTEM CONSISTING OF DOMAIN- SPECIFIC SUB-SYSTEMS

Deniz Canturk and Pinar Senkul

B2C AND C2C E-MARKETPLACES - A Multi-layer/Multi-agent Architecture to Support them R. Miguel, J. J. Castro-Schez, D. Vallejo, C. Glez-Morcillo and V. Herrera

MOBILE E-LEARNING - Support Services Case Study

Catarina Maximiano and Vitor Basto Fernandes

APPLYING FIPA STANDARDS ONTOLOGICAL SUPPORT TO INTENTIONAL-MAS-ORIENTED UBIQUITOUS SYSTEM

Milene Serrano and Carlos José Pereira de Lucena

SELECTING PARTNERS FOR COLLABORATIVE NETWORKS - Mixed Methods Approach Noor Azliza Che Mat, Yen Cheung and Helana Scheepers

\section{Posters}

EXTENDING LEGACY AGENT KNOWLEDGE BASE SYSTEMS WITH SEMANTIC WEB COMPATIBILITIES

Po-Chun Chen, Guruprasad Airy, Prasenjit Mitra and John Yen

$\mathrm{L}^{4} \mathrm{~F}$ : A P2P ITS FOR RECOMMENDING ADDITIONAL LEARNING CONTENTS BY MEANS OF FOLKSONOMIES

Marta Rey-López, Fernando A. Mikic-Fonte, Ana M. Peleteiro, Juan C. Burguillo and Ana Belén

Barragáns-Martínez

ANTECEDENCE GRAPH APPROACH TO CHECKPOINTING FOR FAULT TOLERANCE IN MULTI AGENT SYSTEM

Rajwinder Singh, Ramandeep Kaur and Rama Krishna Challa

A FAULT DETECTION AND RECOVERY SYSTEM FOR DOORAE RUNNING ON HOME NETWORK ENVIRONMENT

SoonGohn Kim and Eung Nam Ko

A CONTRACT-BASED EVENT DRIVEN MODEL FOR COLLABORATIVE SECURITY IN FINANCIAL INFORMATION SYSTEMS

Roberto Baldoni, Georgio Lodi, Gregory Chockler, Eliezer Dekel, Barry P. Mulcahy and Giuseppe Martufi

CASE STUDY: COMPLEMENTS OF MATHEMATICS AND E-LEARNING

A. Hernández Encinas, A. Queiruga Dios, J. Martín Vaquero and J. L. Hernández Pastora 
TheHiddenU - A Social Nexus for Privacy-assured Personalisation Brokerage

G. Kappel, J. Schönböck, M. Wimmer, G. Kotsis, A. Kusel, B. Pröll, W. Retschitzegger, W. Schwinger, R. R.

Wagner and S. Lechner

WHAT, WHY AND HOW TO INTEGRATE - Self Organization within a SOA

Hakima Mellah, Salima Hassas and Habiba Drias

AUTHOR INDEX

169 